\title{
Glypican 3 expression in human normal and neoplastic tissue: a tissue microarray analysis on $\mathbf{4 3 3 8}$ tissue samples D Baumhoer*, LM Terracciano, S Stadlmann and L Tornillo
}

Address: Institut für Pathologie, Universität Basel, Switzerland

* Corresponding author

from 35te Tagung der Pathologen am Oberrhein/35th Meeting of Pathologists of the Upper Rhine Region (PATOR) The Institute of Pathology, University Hospital Freiburg, Germany. I July 2006

Published: I4 March 2007

Diagnostic Pathology 2007, 2(Suppl I):S5 doi:I0.I I86/1746-I596-2-SI-S5

(c) 2007 Baumhoer et al; licensee BioMed Central Ltd.

\begin{abstract}
Aims and methods
Glypican 3 (GPC3) belongs to the glypican family of GPI anchored heparan sulfate proteoglycans, which play a crucial role in cellular growth, cell migration and cell differentiation. Several studies have shown GPC3 to be a highly specific marker for hepatocellular carcinoma (HCC) and for differentiating non- and pre-neoplastic liver disease. To systematically investigate the epidemiology of GPC3 expression in non-neoplastic, pre-neoplastic and neoplastic tissues, we used tissue microarray (TMA) technology to analyze the immunohistochemically detectable expression of GPC3 in 3,678 tissue samples from 132 different tumor categories and 31 non-neoplastic and pre-neoplastic tissue types.
\end{abstract}

Furthermore, GPC3 expression was investigated in an additional TMA containing 405 non-neoplastic, pre-neoplastic and neoplastic liver samples.

\section{Results}

GPC3 expression was found in $23 \%$ of non-neoplastic (liver cirrhosis), in $37 \%$ of pre-neoplastic (low- and highgrade dysplastic nodules) and in $64 \%$ of neoplastic liver disease. Furthermore, testicular non-seminomatous germ cell tumors (55\%), squamous cell carcinoma of the lung (54\%), liposarcoma (52\%), cervical intraepithelial neoplasia (CIN) III (41\%), melanoma (29\%) and schwannoma (26\%) also revealed consistent expression of GPC3.

\section{Conclusion}

This study provides a comprehensive overview on the expression of GPC3 in normal and cancerous tissue. Among neoplastic tissue, our data underline the role of GPC3 in hepatocellular carcinogenesis and suggest a potential role of GPC3 as a therapeutic target in these tumors. Moreover, several non-hepatic tumors can also show GPC3 positivity. 